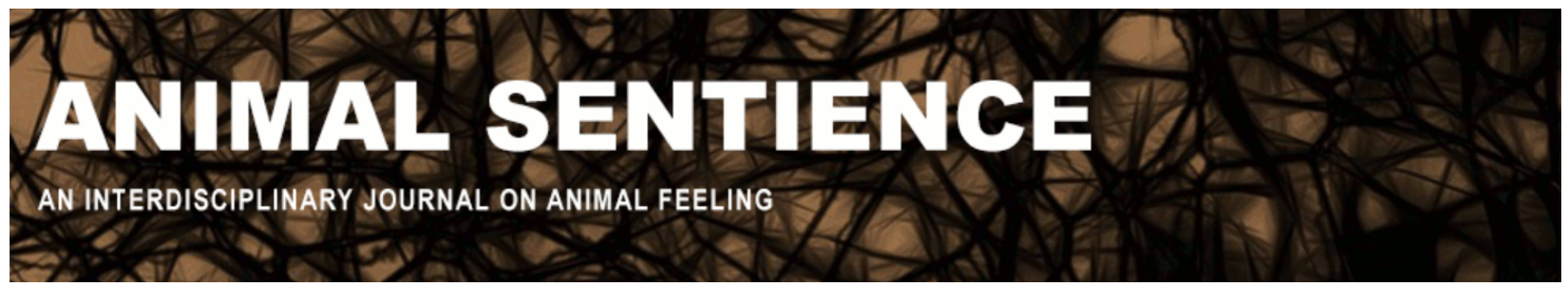

Smith, Allison M. and Reese, Jacy (2016) An empirical perspective on animal advocacy. Animal Sentience 7(12)

DOI: $10.51291 / 2377-7478.1102$

Date of submission: 2016-03-18

Date of acceptance: 2016-03-24

(c)

This article has appeared in the journal Animal

Sentience, a peer-reviewed journal on animal

cognition and feeling. It has been made open access,

free for all, by WellBeing International and deposited

in the WBI Studies Repository. For more information,

please contact

wbisr-info@wellbeingintl.org.

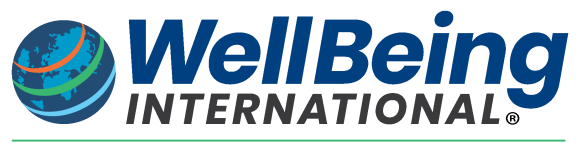

SOLUTIONS FOR PEOPLE, ANIMALS AND ENVIRONMENT 


\title{
An empirical perspective on animal advocacy
}

Commentary on $\mathrm{Ng}$ on Animal Suffering

\author{
Allison M. Smith \\ Jacy Reese \\ Animal Charity Evaluators
}

\begin{abstract}
Ng}$ (2016) lists some modest examples of goals that animal advocates could work towards. We provide examples of more ambitious animal advocacy strategies that are successful now, and strategies that researchers can use to engage productively with animal advocates. We also agree with $\mathrm{Ng}$ and some other commentators that animal advocates and researchers should prioritize the interests of individual wild animals over the preservation of nonsentient entities.
\end{abstract}

\begin{abstract}
Allison Smith is Director of Research at Animal Charity Evaluators. She leads a team that researches interventions and organizations to determine how advocates can do the most good for animals. http://www.animalcharityevaluators.org/

Jacy Reese is a Research Associate at Animal Charity Evaluators and a leading voice in the "effective animal advocacy" community. His work has been featured in Huffington Post, Vox, Salon, and elsewhere. http://www.jacyreese.com
\end{abstract}
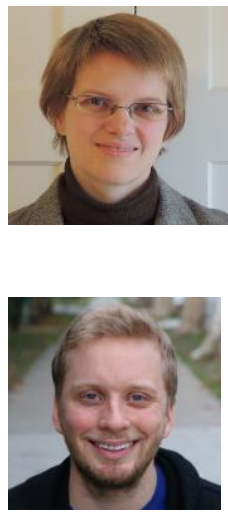

$\mathrm{Ng}$ (2016) makes an important contribution in noting that science should concern itself with maximizing the well-being of nonhuman animals. While the equivalent concern for humans is the focus of multiple disciplines (medicine, development economics, etc.), nonhuman animals are more often viewed as a means to an end, whether it be the general advancement of knowledge, human concerns, or the preservation of ecosystems. However, as Ng notes, the neuroanatomical and behavioral evidence supports the common sense perception that a large variety of nonhuman animals - at least all vertebrates - are capable of feeling, so minimizing their suffering and maximizing their flourishing is an important goal from a variety of moral perspectives.

We can consider bigger outcomes in animal advocacy. Some of the other commentators complain that Ng's goals were too modest. Several offer criticism specifically of the "welfarist" approach; Marks (2016), for example, asks, "Need animal advocacy be considered a zero sum proposition that requires our commitment to only one or the other of animal welfare versus animal liberation?" He apparently concludes that this is in fact the case, making the remainder of his commentary an argument against welfarism. From our perspective as activists and researchers, this distinction makes little, if any, difference in animal advocacy strategy. 
For example, we believe that all the common philosophical positions lead to agreement with other commentaries (and $\mathrm{Ng}$ himself) that $\mathrm{Ng}^{\prime}$ s suggested ways to help animals in low-cost, tractable ways are too modest and "just a starting position" - we can, and should, be willing to work towards larger outcomes - as shown by recent successes of animal advocacy groups. For example, advocates in India spearheaded a four-year ban on sports involving bulls; although the ban has ended, its enactment suggests that focusing solely on prohibiting the cruelest features of animal entertainment is an unnecessary restriction on the scope of advocates' activities and demands (Muruganandham, 2016).

Similarly, advocates for farmed animals should consider outcomes beyond increased cage sizes and increased awareness of the health benefits of eating less meat. Indeed, advocacy groups have had success in diverse methods of challenging the animal agriculture system, including increasing cage sizes or removing cages altogether, challenging the use of animals whose quality of life is necessarily low due to genetic factors (as Leadbeater (2016) mentions), increasing the availability and prominence of plant-based alternatives, and educating the public about the dangers to animals, humans, and the environment inherent in the continuation of the current food system (Barclay, 2015; Marshall \& Green, 2015; Mohan, 2016; Neilson, 2016).

Our research at Animal Charity Evaluators suggests that projects addressing these outcomes can be extremely cost-effective. In addition to direct outcomes, such as reducing the number of animals suffering in animal agriculture and eliminating some of the cruellest practices, we think interventions like corporate outreach and undercover investigations can facilitate big-picture achievements such as the eventual abolition of animal agriculture, largely by building the animal advocacy movement itself and setting animal-friendly precedents in policy and social norms.

Recognizing wild animals as individuals. We agree with $\mathrm{Ng}^{\prime}$ s suggestion that "without ignoring wild animals altogether, our initial emphasis should be more on farmed animals." We appreciate that Johannsen (2016) takes this view further, suggesting that "animal rights theorists should acknowledge that their position also requires a hypothetical commitment to intervening in the wild."

We see animal suffering - especially the most intense forms like confinement, violent death, or serious illness - as morally horrific, regardless of its cause. This view comes naturally once one takes the perspective of the wild animal, who indicates in every part of his behavior that he strongly opposes his natural suffering. This recognition of animals as morally relevant persons with their own interests also leads to our opposition to human-caused suffering, and it's the key reason we take a view different from that of Marks who sees wild animal welfare and preferences as "beside the point."

Academia can help animals in a number of ways. $\mathrm{Ng}$ offers suggestions as to how animal welfare advocates can be more effective, focusing primarily on two points which are compelling from an academic perspective: avoiding hyperbole and promoting technological progress that would enable us to be more effective in promoting both human and animal welfare. While these 
are good suggestions, on their own they reinforce a limiting view of the interaction between academics and advocates, one in which academics are restricted to advising advocates on the intellectual rigor of their approach, while advocates may be informed by academia but cannot offer reciprocal guidance that would help lead to the production of knowledge which could be applied to current problems. We feel it is important to recognize the full potential value of academic research for animal advocates and want to offer some possible strategies for academics:

Most directly, scholars with expertise or interest in social sciences can provide empirical evidence to inform tactical decisions. Scholars could enhance advocates' effectiveness by empirically testing methods of outreach and social change, and by communicating their findings to a broad audience of animal advocates. Studies could also be carried out collaboratively, with scholars providing research expertise and advocacy groups providing resources that allow scholars to work with large sample sizes in the field. They can also synthesize social movement information, psychological theories, and other streams of evidence to provide strategic guidance.

Welfare biologists can also help advocates work in the most effective ways, by identifying the incremental changes, such as larger cages or less harmful breeding, that would most benefit animals as we work towards more fundamental improvements.

Legal scholars can work with groups like the Nonhuman Rights Project to enhance and further the case for appropriate moral consideration of animals in the current legal framework.

Animal ethicists, other philosophers, and other academics can work to identify arguments or methods of persuasion that can help others in their field appreciate the moral worth of animals and give them proper consideration.

We are very excited about further collaboration between advocates and academics. Animal Charity Evaluators will be hosting a research symposium at Princeton University in November 2016 to facilitate this partnership. We invite interested scholars to join us there.

\section{References}

Barclay, E. (2015, December 30). The year in eggs: everyone's going cage-free, except supermarkets. National Public Radio.

Bruers, S. (2016). Animal suffering and human bias. Animal Sentience 2016.084

Johannsen, K. (2016). Animal welfare at home and in the wild. Animal Sentience 2016.085 
Leadbeater, S. R. B. (2016). Animal suffering calls for more than a bigger cage. Animal Sentience 2016.071

Marks, J. (2016). End-state welfarism. Animal Sentience 2016.075

Marshall, L., \& Green, C. (2015). The ghosts in our machine impact report.

Mohan, G. (2016, February 11). Hampton Creek, creator of egg-free Just Mayo, gains a victory in the food wars. Los Angeles Times.

Muruganandham, T. (2016, January 8). Centre lifts ban on Jallikattu, bullock cart race in TN, six other states. The New Indian Express.

Neilson, Z. (2016, January 29). The case of the exploded Dutch chickens. Sustainable Food Trust.

Ng, Y-K. (2016). How welfare biology and commonsense may help to reduce animal suffering. Animal Sentience 2016.007 